\title{
Outcomes of an intervention program for family physicians on well-child care for children under 5 years in Suez Canal region, Egypt
}

Hazem A. Sayed Ahmed ${ }^{1}$ (B), Hassan Abdelwahid Ali', Badr Mosbah², Mohamed Hany Kamel Shehata ${ }^{3}$, Jaffer Shah ${ }^{4,5^{*}}$ (D) and Mosleh Abdel Rahman Ismail ${ }^{1}$

\begin{abstract}
Background: Family physicians play a critical role in providing well-child care (WCC) in Egypt to children under five. Family physicians' knowledge, attitudes, and practices (KAP) on WCC must be appropriately developed to optimize health status and developmental potential in children. The study aimed to evaluate the effect of an innovative, 6-month educational training program on the KAP of family physicians toward WCC. This pre-post interventional study was conducted from September 2014 to March 2016 on a convenience (Suez Canal University) sampling of 39 family physicians who were under training in the Family Medicine Department at the Faculty of Medicine Suez Canal University. After 6 months of implementing the training program, KAP toward WCC was assessed by a 79-item questionnaire at baseline.
\end{abstract}

Results: The overall mean percentage of participants' KAP scores was statistically and significantly increased from $23.68 \% \pm 13.68 \%, 67.15 \% \pm 6.75 \%$, and $40.98 \% \pm 12.24 \%$ to $88.46 \% \pm 8.09 \%, 88.62 \% \pm 5.17 \%$, and $71.79 \% \pm 14.63 \%$, respectively $(p<0.001)$. Recognizing the appropriate anticipatory guidance for the use of car seats made up the epitome of what was lacking in posttest knowledge (53.8\%). Tendency of performing red reflex testing especially reduced refinement in posttest attitudes (53.8\%). The least improved post-intervention practices were anticipatory guidance (7.7\%), examination for developmental hip dysplasia (28.2\%), and caries (43.6\%), eliciting parents' concerns for hearing and speech (38.5\%) and vision screening (38.5\%).

Conclusions: The educational program had positive effects on family physicians'KAP toward well-child care for children under five. Further interventions are needed for improving the family physicians' practices of sensory screening, assessment of hip dysplasia, oral health, and anticipatory guidance.

Keywords: Integrated primary care, Pediatric primary care, Well child care, Early childhood development

\section{Background}

Children are both the present and the future of nations [1]. Children under 5 years of age make up about $13.6 \%$ of the Egyptian population [2]. The first 5 years of children's

\footnotetext{
*Correspondence: jaffer.shah@health.ny.gov

${ }^{5}$ New York State Department of Health, Albany, NY, USA

Full list of author information is available at the end of the article
}

lives are a critical period for their survival, growth, and lifelong development [3]. Health promotion for children under 5 years is essential for the lifelong health and wellbeing of individuals and countries [4].

Family physicians (FPs) have a unique to provide evidence-based preventive services for children and establish an ongoing relationship with the children and their families through well-child visits. These 
preventive services include clinical examinations (focusing on growth and development monitoring), screening, immunizations, micronutrient supplementations, and anticipatory guidance $[5,6]$.

In developing countries, previous studies have examined KAP/education of FPs/primary health care (PHC) providers on growth monitoring [7], child development $[8,9]$, sensory screening $[10,11]$, and chemoprevention, e.g., vitamin D supplementation for infants [12]. Some studies revealed that FPs' knowledge toward oral health was limited and insufficient for postgraduate training [13].

Egypt has witnessed a dramatic decline in its under- 5 mortality rate and has achieved the millennium developmental goal 4 in 2008 [14]. Vaccination coverage, integrated management of child illness, and safe water supply and sanitation might have all played roles in reducing the mortality rate [15]. Therefore, focusing on additional pediatric preventive services to enhance the development of children is warranted.

No study has previously examined family physicians' KAP of well-child care for children under five in Suez Canal region, Egypt. This study aimed to evaluate the effectiveness of an innovative interventional program on family physicians' KAP toward well-child care for children under five in Suez Canal region.

\section{Methods}

A pre-post interventional study was conducted from September 2014 to March 2016. This interventional study was held in the Family Medicine Department at the Faculty of Medicine in Suez Canal University (FOM-SCU). The assessment of participants' practices was performed in training family practice centers (FPCs) affiliated with the Family Medicine Department, Faculty of Medicine, Suez Canal University (FOM-SCU); in Port Said (2 centers), Ismailia (3 centers), and Suez governorates (4 centers).

Authors emailed FPs to participate in the study. A convenience sampling of 39 FPs was recruited (the response rate was 63.93\%), all of whom regularly enrolled in classic postgraduate programs at the Family Medicine Department in Suez Canal University (FOM-SCU) and participated in this intervention affiliated with it as well as the Ministry of Health and Population (MOHP). The study excluded FPs who did not work in the Suez Canal University (FOM-SCU) region even though they were under training at the Family Medicine Department, Suez Canal University (FOM-SCU). Those FPs were not adherent to attend the training program, nor did they send one of the department's pretest or posttest staff. The study was conducted in three phases: preparatory, implementation, and evaluation and scoring of the questionnaire's phases.

\section{Preparatory phase}

During the preparatory phase, the questionnaire, which was based on relevant literature, was designed by the researchers to close the gaps between the national and some international guidelines [4, 16-24]. This questionnaire consisted of four parts (see the Supplementary file). It included the participants' socio-demographic data and the KAP of them toward well-child care for children under 5 years in the Suez Canal area. The first parts of this questionnaire were self-reported by FPs and the fourth part (practices) was assessed by the first author via an observational checklist during the 12 months of wellchild visits. This was because every well-child visit has its unique items of assessment in literatures and this visit included the largest quantity of targeted training practices in the present study.

Each part of the questionnaire's KAP consisted of three subscales, e.g., growth and developmental monitoring, risk assessment and screening, vaccination, chemoprevention, and counseling for children under five. The participants' KAP was assessed by 30 multiple-choice questions (MCQs), 33 items of a five-point Likert scale (with options of strongly disagree, disagree, no opinion, agree, and strongly agree), and 15 items of a 5-point rating scale (with options of clear unperformed, partially unperformed, borderline performed, partially performed, and clear performed), respectively.

The questionnaire was validated by three experts in family medicine. A pilot study included ten participants who were included in our sample size; it tested the questionnaire's reliability and assessed the understandability of its items, clearness, acceptability, and meaning to the subjects. Cronbach's alpha was used as an internal consistency estimate of the reliability of the KAP questionnaire $(0.77,0.80$, and 0.81 , respectively). Completion of this questionnaire lasted from 40 to $50 \mathrm{~min}$.

\section{Designing of the intervention}

The principal investigator designed this intervention based on relevant literature $[4,16-24]$ and took into consideration the result of the pretest. The intervention designed was an act of face-to-face learning and it was conducted through days as mentioned later. The designed intervention was sent to a panel of three experts in family medicine to get their feedback using the Delphi technique. They suggested more use of the role-playing and assignments. 


\section{Implementation phase}

The principal investigator provided this intervention as a workshop, which was to be repeated three times in the department of family medicine. Every workshop lasted 2 days. The first day of this intervention consisted of four sessions and reflection at the end of the day. These sessions included a program overview and orientation, introduction to well-child care for children under five, growth and developmental monitoring, and risk assessment and screening (first part). The second day consisted of reflection on the first day as well as the same four sessions and reflection at the end of the second day. These sessions included risk assessment and screening (second part), vaccination and chemoprevention, counseling and anticipatory guidance, and consultation at the well-child care visits.

Face-to-face training included appropriate teaching and learning methods such as interactive lectures, role-playing, videos, exercises, and assignments. Each day the workshops ran from 9.30 a.m. to 2 p.m. The number of attendants made up an appropriate/ session (10-15). The principal investigator provided these workshops under the supervision of other authors.

\section{Evaluation and scoring of questionnaires phase}

The percentage of correct answers in the MCQs was calculated as a representative of the knowledge score for each participant. While each response for Likert items was scored on a scale of 1 (strongly disagree) to 5 (strongly agree), each response for reverse-coded Likert items was re-coded and scored on a scale of 5 (strongly disagree) to 1 (strongly agree). For each individual, the score of attitudes' responses was summed and converted into a percentage $(20-100 \%)$ to represent the attitudes score.

Each item for the rating scale of practices was scored on a scale of 0 (clear unperformed) to 4 (clear performed). For each individual, the score of items was summed and converted into a percentage to represent the participant's practices score. The scores of knowledge and practices were considered acceptable if they were $\geq 60 \%$, according to the working bylaws in FOMSCU. The scores of attitudes were considered positive attitudes if they were $\geq 80 \%$. These data were collected at baseline after 6 months of participation in interventional study.

\section{Statistical analysis}

Data was analyzed by the Statistical Package for Social Sciences (SPSS) version 20. A paired $t$ test was used to compare the means of participants' KAP. The 5-point scale items of attitudes were condensed into two categories, after which the McNemar's test was used to compare participants' knowledge and attitude changes in the study. The 5-point rating scale items of practices were condensed into three categories and the marginal homogeneity was used to compare the participants' difference of practices in the pre-post intervention.

Pearson's correlation coefficient was used to assess correlation between participants' KAP. Multiple linear regression was used to detect predictors of posttest practices score (dependent variable) and independent variables (affiliation, posttest knowledge score, duration of practice, and posttest attitudes score).

\section{Results}

The current study included 39 FPs, most of whom were older than 30 years. Female FPs constituted about $76.9 \%$ of the participants (Table 1). The overall mean percentage of participants' KAP scores was statistically and significantly increased from $23.68 \% \pm 13.68 \%, 67.15 \% \pm 6.75 \%$, and $40.98 \% \pm 12.24 \%$ in the pretest to $88.46 \% \pm 8.09 \%$, $88.62 \% \pm 5.17 \%$, and $71.79 \% \pm 14.63 \%$ in the posttest, respectively ( $p$ value $<0.001)$.

Table 1 Baseline characteristics of participants in the pre-post intervention

\begin{tabular}{lll}
\hline Characteristics & $\boldsymbol{n}$ & $\%$ \\
\hline Age $^{\mathrm{a}}$ & & \\
$\quad<30$ year & 17 & 43.6 \\
$\quad \geq 30$ year & 22 & 56.4 \\
$\begin{array}{l}\text { Gender } \\
\text { Male }\end{array}$ & 9 & 23.1 \\
$\quad$ Female & 30 & 76.9 \\
Affiliation & & \\
$\quad$ SCU & 27 & 69.2 \\
$\quad$ MOHP & 12 & 30.8 \\
Governorate of practice & & \\
$\quad$ Port Said & 15 & 38.5 \\
$\quad$ Ismailia & 18 & 46.2 \\
$\quad$ Suez & 6 & 15.4 \\
Location of practice & & \\
$\quad$ Urban & 17 & 41.0 \\
$\quad$ Rural \\
Duration of practice \\
$\quad<5$
\end{tabular}

${ }^{a}$ Mean of age $30.5(S D \pm 4.2)$ years 
Table 2 Comparison of achieving acceptable level of participants' KAP in the pre-post intervention

\begin{tabular}{|c|c|c|c|c|c|}
\hline \multirow[t]{2}{*}{ Domain } & \multicolumn{2}{|c|}{ Pretest $(n=39)$} & \multicolumn{2}{|c|}{ Posttest $(n=39)$} & \multirow[t]{2}{*}{ McNemar $p$ value } \\
\hline & $n$ & $\%$ & $n$ & $\%$ & \\
\hline \multicolumn{6}{|l|}{ Knowledge domain } \\
\hline Growth and developmental monitoring & 2 & 5.1 & 38 & 97.4 & $<0.001^{*}$ \\
\hline Risk assessment and screening & 0 & 0 & 38 & 97.4 & $<0.001^{*}$ \\
\hline Vaccination, chemoprevention, and counseling & 4 & 10.3 & 39 & 100 & $<0.001^{*}$ \\
\hline Acceptable level of total knowledge score & 0 & 0 & 39 & 100 & $<0.001^{*}$ \\
\hline \multicolumn{6}{|l|}{ Attitudes domain } \\
\hline Growth and developmental monitoring & 2 & 5.1 & 38 & 97.4 & $<0.001^{*}$ \\
\hline Risk assessment and screening & 1 & 2.6 & 28 & 71.8 & $<0.001^{*}$ \\
\hline Vaccination, chemoprevention, and counseling & 10 & 25.6 & 37 & 94.9 & $<0.001^{*}$ \\
\hline Acceptable level of total attitudes'score & 1 & 2.6 & 37 & 94.9 & $<0.001^{*}$ \\
\hline \multicolumn{6}{|l|}{ Practices domain } \\
\hline Growth and developmental monitoring & 15 & 38.5 & 34 & 87.2 & $<0.001^{*}$ \\
\hline Risk assessment and screening & 1 & 2.6 & 19 & 48.7 & $<0.001^{*}$ \\
\hline Vaccination, chemoprevention, and counseling & 2 & 5.1 & 13 & 33.3 & $<0.001^{*}$ \\
\hline Acceptable level of total practices'score & 3 & 7.7 & 33 & 84.6 & $<0.001^{*}$ \\
\hline
\end{tabular}

*Statistically significant at $p$ value $<0.05$

Most of the participants significantly acquired an acceptable level of KAP on growth and developmental monitoring after the intervention. Participants' practices on vaccination, chemoprevention, and counseling, in addition to risk assessment and screening, were domains that were not addressed enough in comparison to the rest after the intervention (Table 2).

All knowledge items toward growth and developmental monitoring after the intervention were significantly

Table 3 Correct participants' knowledge in the pre-post intervention

Knowledge

Pretest $\left(n=\frac{l}{\text { Posttest }(n=}\right.$ McNemar $p$ value
$\begin{array}{ll}39) \\ n \quad \%\end{array} \frac{39)}{n \quad \%}$

\section{Growth and developmental monitoring}

Estimating the adjusted corrected age for premature infant Interpreting the plotted points for growth on the 2006 WHO growth chart z-score Interpreting the trend of simultaneously sloped growth curves for weight and length Recognizing the warning date to gain the lost weight in newborn Identifying a proper age for infant can ride a tricycle and had difficulty in copying a square Expecting the normal language development for 2 years old child Applying knowledge for diagnosis of global developmental delay Identifying physician's concern for child's speech and language Identifying indication of referral for child's motor development

\section{Risk assessment and screening}

Applying knowledge to identify 3 risk factors for speech and language delay Recognizing the level of evidence for speech and language screening in PHC Applying knowledge to identify high risk group for hearing loss Identifying the sequence of neonatal hearing loss screening Recognizing correctly the approach to screen vision for 3 years child Deciding referral of child aged 6 months with isotropic eye to ophthalmologist Recognizing the starting age for screening of anemia in Egyptian children Recognizing the level of USPSTF recommendation for DDH screening Recognizing the appropriate starting age for autism screening

$\begin{array}{lllll}8 & 20.5 & 37 & 94.9 & <0.001^{*} \\ 3 & 7.7 & 38 & 97.4 & <0.001^{*} \\ 4 & 10.3 & 25 & 64.1 & <0.001^{*} \\ 14 & 35.9 & 34 & 87.2 & <0.001^{*} \\ 16 & 41.0 & 39 & 100.0 & <0.001^{*} \\ 16 & 41.0 & 38 & 97.4 & <0.001^{*} \\ 12 & 30.8 & 38 & 97.4 & <0.001^{*} \\ 2 & 5.1 & 24 & 61.5 & <0.001^{*} \\ 14 & 35.9 & 37 & 94.9 & <0.001^{*} \\ & & & & \\ 3 & 7.7 & 30 & 76.9 & <0.001^{*} \\ 7 & 17.9 & 36 & 92.3 & <0.001^{*} \\ 4 & 10.3 & 36 & 92.3 & <0.001^{*} \\ 3 & 7.7 & 29 & 74.4 & <0.001^{*} \\ 8 & 20.5 & 35 & 89.7 & <0.001^{*} \\ 25 & 64.1 & 36 & 92.3 & 0.013^{*} \\ 15 & 38.5 & 36 & 92.3 & <0.001^{*} \\ 8 & 20.5 & 37 & 94.9 & <0.001^{*} \\ 6 & 15.4 & 37 & 94.9 & <0.001^{*}\end{array}$


changed in statistics according to Table 3 ( $p$ value < 0.001). The least improved posttest of participants' knowledge was recognizing the appropriate anticipatory guidance for the use of car seats (53.8\%). About nine out of every ten $(89.7 \%)$ participants in the posttest reported tendency of using developmental milestones in comparison to $41 \%$ of them in the pretest. The percentage of reporting tendency of asking about parents' concerns regarding development of their children was increased from $14 \%$ in the pretest to $100 \%$ in the posttest.

In the posttest, $53.8 \%$ of participants reported tendency of performing red reflex testing at each wellbaby/child care visit in contrast to $17.9 \%$ of them in the pretest (Table 4). None of the participants performed vision screening for children prior to intervention, while $38.5 \%$ of them conducted it after intervention. In the posttest, the percentages of the participants who counseled parents of children for 2 or $\geq 3$ anticipatory guidance messages were $25.6 \%$, $7.7 \%$, respectively (Table 5 ).

There was a statistically significant correlation between posttest practices and posttest knowledge, and it was a strong positive relationship (Pearson correlation $=0.627$ ). The moderate positive relationship between posttest practices and posttest attitudes was present, and this relationship was statistically significant (Pearson correlation $=0.336$ ). A statistically significant correlation between knowledge and attitudes was present, and it was a moderate positive relation (Pearson correlation $=0.325)$. Affiliation and posttest knowledge scores were statistically significant predictors $(p$ value $<0.05)$ for the posttest practices score.

\section{Discussion}

This pre-post interventional study was conducted to assess the KAP of FPs on well-child care for children under five in the Suez Canal area before and after the implementation of pre-post intervention. Participants' KAP on well-child care was significantly improved after the intervention, but their attitudes and practices about risk assessment and screening, as well as practices of chemoprevention and counseling, require further improvement.

Prior to this intervention, poor knowledge, poor attitudes, and poor practice levels were detected in the pre-intervention survey on well-child care. These poor pre-intervention phase results may be the result of inadequate training and practice on well-child care, inadequate equipment, deficiency of well-child care issues in undergraduate and postgraduate curriculums, out-of-date national guidelines, and weak systems in providing wellchild care with the exception of the provision of vaccination and screening for congenital hypothyroidism and phenylketonuria.

The current intervention effectively improved the participants' KAP on growth monitoring. Service training of FPs on growth monitoring, especially plotting and interpretation of growth charts in addition to appropriate management of the growth problems, is needed to acquire them an acceptable level of knowledge and skills toward this subject [7].

Participants' KAP on developmental monitoring was also improved after participating in the present study. These findings are congruent with the findings of the Brazilian study, which revealed that PHC professionals' knowledge and practices about child development were improved after participation in continuing education programs [9].

Table 4 Positive attitudes of participants toward risk assessment and screening for children under-5 in the pre-post intervention

\begin{tabular}{|c|c|c|c|c|c|}
\hline \multirow[t]{2}{*}{ Attitudes } & \multicolumn{2}{|c|}{ Pretest $(n=39)$} & \multicolumn{2}{|c|}{ Posttest $(n=39)$} & \multirow[t]{2}{*}{ McNemar $p$ value } \\
\hline & $n$ & $\%$ & $n$ & $\%$ & \\
\hline Referral child with parental hearing and language concerns & 12 & 30.8 & 37 & 94.9 & $<0.001^{*}$ \\
\hline Screening of neonatal hearing deafness loss has benefits & 23 & 59.0 & 36 & 92.3 & $<0.001^{*}$ \\
\hline Tendency of referral neonate for hearing loss screening & 11 & 28.2 & 30 & 76.9 & $<0.001^{*}$ \\
\hline Tendency of inquiring about parents' concerns for vision of their children & 15 & 38.5 & 36 & 92.3 & $<0.001^{*}$ \\
\hline $\begin{array}{l}\text { Performing of vision screening (corneal light reflex and the cover-uncover test) is } \\
\text { difficult }\end{array}$ & 23 & 59.0 & 36 & 92.3 & $<0.001^{*}$ \\
\hline Tendency of performing red reflex testing at each well baby/child care visit & 7 & 17.9 & 21 & 53.8 & $0.001^{*}$ \\
\hline Performing age-appropriate screening for anemia is essential & 28 & 71.8 & 38 & 97.4 & $0.002^{*}$ \\
\hline Tendency of performing age-appropriate screening for anemia & 24 & 61.5 & 39 & 100 & $<0.001^{*}$ \\
\hline Conducting the Barlow and Ortolani tests is difficult" & 15 & 38.5 & 34 & 87.2 & $<0.001^{*}$ \\
\hline
\end{tabular}

?.Reverse-coded Likert items

*Statistically significant at $p$ value $<0.05$ 
Table 5 Assessment of participants' practices in the pre-post intervention

\begin{tabular}{|c|c|c|c|c|c|c|c|c|}
\hline \multirow[t]{2}{*}{ Practices } & \multirow[t]{2}{*}{ Pre/post } & \multicolumn{2}{|c|}{$\begin{array}{l}\text { Clear/partial } \\
\text { unperformed }\end{array}$} & \multicolumn{2}{|c|}{$\begin{array}{l}\text { Borderline } \\
\text { performed }\end{array}$} & \multicolumn{2}{|c|}{$\begin{array}{l}\text { Clear/partial } \\
\text { performed }\end{array}$} & \multirow[t]{2}{*}{ MH $p$ value $^{a}$} \\
\hline & & $n$ & $\%$ & $n$ & $\%$ & $n$ & $\%$ & \\
\hline \multicolumn{9}{|l|}{ Growth and developmental monitoring } \\
\hline \multirow[t]{2}{*}{ Exploring concerns for development } & Pre & 38 & 97.4 & 0 & 0 & 1 & 2.6 & $<0.001^{*}$ \\
\hline & Post & 8 & 20.5 & 0 & 0 & 31 & 79.5 & \\
\hline \multirow[t]{2}{*}{ Milestones assessment } & Pre & 7 & 17.9 & 24 & 61.5 & 8 & 20.5 & $<0.001^{*}$ \\
\hline & Post & 2 & 5.1 & 15 & 38.5 & 22 & 56.4 & \\
\hline \multirow[t]{2}{*}{ Past history assessment } & Pre & 12 & 30.8 & 0 & 0 & 27 & 69.2 & $0.002^{*}$ \\
\hline & Post & 2 & 5.1 & 0 & 0 & 37 & 94.9 & \\
\hline \multirow[t]{2}{*}{ Family history assessment } & Pre & 28 & 71.8 & 9 & 23.1 & 2 & 5.1 & $<0.001^{*}$ \\
\hline & Post & 0 & 0 & 8 & 20.5 & 31 & 79.5 & \\
\hline \multirow[t]{2}{*}{ Socioeconomic assessment } & Pre & 21 & 53.8 & 7 & 17.9 & 11 & 28.2 & $<0.001^{*}$ \\
\hline & Post & 2 & 5.1 & 2 & 5.1 & 35 & 89.7 & \\
\hline \multirow[t]{2}{*}{ Nutritional assessment } & Pre & 3 & 7.7 & 1 & 2.6 & 35 & 89.7 & 0.180 \\
\hline & Post & 2 & 5.1 & 0 & 0 & 38 & 94.9 & \\
\hline \multirow[t]{2}{*}{ Plotting growth measurement } & Pre & 0 & 0 & 1 & 2.6 & 38 & 97.1 & NA \\
\hline & Post & 0 & 0 & 0 & 0 & 39 & 100 & \\
\hline \multicolumn{9}{|l|}{ Risk assessment and screening } \\
\hline \multirow[t]{2}{*}{ Anemia assessment } & Pre & 9 & 23.1 & 19 & 48.7 & 11 & 28.2 & $<0.001^{*}$ \\
\hline & Post & 0 & 0 & 6 & 15.4 & 33 & 84.7 & \\
\hline \multirow[t]{2}{*}{ Screening of vision } & Pre & 38 & 97.4 & 1 & 2.6 & 0 & 0 & $<0.001^{*}$ \\
\hline & Post & 17 & 43.6 & 7 & 17.9 & 15 & 38.5 & \\
\hline \multirow[t]{2}{*}{ Eliciting concerns (speech and hearing) } & Pre & 39 & 100 & 0 & 0 & 0 & 0 & $<0.001^{*}$ \\
\hline & Post & 24 & 61.5 & 0 & 0 & 15 & 38.5 & \\
\hline \multirow[t]{2}{*}{ Examination of teeth } & Pre & 16 & 41 & 17 & 43.6 & 6 & 15.6 & $<0.001^{*}$ \\
\hline & Post & 6 & 15.4 & 16 & 41 & 17 & 43.6 & \\
\hline \multirow[t]{2}{*}{ Examination of hip } & Pre & 34 & 87.2 & 2 & 5.1 & 3 & 7.7 & $0.016^{*}$ \\
\hline & Post & 28 & 71.8 & 0 & 0 & 11 & 28.2 & \\
\hline \multicolumn{9}{|c|}{ Vaccination, chemoprevention, and counseling } \\
\hline \multirow[t]{2}{*}{ Vaccination assessment } & Pre & 0 & 0 & 7 & 17.9 & 32 & 82.1 & NA \\
\hline & Post & 0 & 0 & 0 & 0 & 39 & 100 & \\
\hline \multirow[t]{2}{*}{ Inquiring about chemoprevention } & Pre & 7 & 17.9 & 22 & 56.4 & 10 & 25.6 & $<0.004^{*}$ \\
\hline & Post & 1 & 2.6 & 24 & 61.5 & 14 & 35.9 & \\
\hline \multirow[t]{2}{*}{ Providing counseling } & Pre & 37 & 94.9 & 1 & 2.6 & 1 & 2.6 & $0.001^{*}$ \\
\hline & Post & 26 & 66.7 & 10 & 25.6 & 3 & 7.7 & \\
\hline
\end{tabular}

${ }^{\mathrm{a}} \mathrm{MH}$ marginal homogeneity test

*Statistically significant at $p<0.05$

NA not applicable

After this intervention, participants became more knowledgeable about the interpreting of growth on the 2006 WHO growth charts' z-score, estimation of gestational age for premature babies, diagnosis of global developmental delay, identifying of the appropriate age milestones, physicians' concern for children's speech and language, and indication of referral for children's motor development. There was no similar interventional study to make a sound comparison with.
After this intervention, nearly four out of five participants asked about parents' concerns for development. This finding was higher than the finding of the National Survey of Children's Health, USA, which revealed that more than half of the physicians or other health care providers asked about parents' concerns for development of children aged 10-47 months [25]. This might be due to the fact that this current study was based on an observational checklist while the survey's result was based on parents reporting their questions they asked physicians 
regarding concerns for their children's learning, development, or behavior.

In the pretest of the current study, the clinical assessment of risk factors for child development needed to have improved results, especially through assessing family as well as socioeconomic risk factors due to the fact that some physicians are less knowledgeable regarding the family risk factors' effect on developmental difficulties, as they had less appreciation of socioeconomic risk factors for growth and development. These issues were improved after implementing the intervention.

Despite the fact that FPs should elicit any parents' concerns about their children's speech and language [20], none of the participants elicited these concerns prior to the current intervention. After the intervention, less than two-fifths of the participants inquired about parents' concerns for language and hearing. This poor practice might have been due to some participants thinking that parents would complain if their children had language or hearing problems; in addition, some physicians relied on their clinical judgment for early detection of hearing loss.

The suboptimal level of knowledge and attitudes toward hearing screening among participants in the pretest might be due to a lack of adequate training and the absence of the national program for early detection and intervention of hearing impairment.

Participants' practices toward vision screening/examination in the present study needed to be improved; it could be because of a lack of adequate training and equipment (e.g., direct ophthalmoscope or torches). This reflected that re-training is needed for vision screening and examination in addition to the availability of the required equipment. In another Turkish study, FPs were shown to also need educational seminars on this topic. Just as well, infrastructure in FPCs should be established to implement detailed eye screening like those in developed countries [26].

The pretest of the current study revealed that the participants' KAP toward developmental dysplasia of the hip (DDH) needed to be changed. While there was a significant improvement of the tested knowledge and attitudes toward this issue after training, only a little more than a quarter of the participants actually examined hips for developmental dysplasia. This might be due to a lack of training on this issue, and most of the participants might have felt they should not do it because of DDH screening having insufficient evidence.

In the pretest of the present study, about more than one-eighth of the participants examined teeth for caries in contrast to more than two-fifths of them in the posttest. This poor practice reflected that participants did not appreciate one of the most significant health problems for children. There was a lack of training, and this problem might not have been addressed enough in the intervention.

In the current study, participants inquired about one micronutrient supplementation (iron supplements) or two (iron and vitamin D supplementations). Inquiring about vitamin A supplementations was a rare practice; this should be improved by reviewing children's cards for this issue.

Prior to the present intervention, about one out of every twenty participants counseled parents regarding $\geq$ 2 anticipatory guidance topics, in contrast to one-third of them after this intervention. The provided anticipatory guidance can be improved by involving nurses, the use of brochures and booklets, and re-training on oral health and child safety and development themes.

A previous survey regarding anticipatory guidance topics, which was discussed during health maintenance visits for children aged 2-11 years, revealed that about one-fifth of the providers reported discussing $\leq 4$ topics during the well-care visit. More than half of providers reported discussing 5-8 topics, and nearly three out of every ten providers reported discussing $\geq 9$ topics [27]. The discrepancy of findings between the current study and that study might be due to different health system deliveries of under- 5 well-child care.

Affiliation with the Family Medicine Department at the FOM-SCU was the most powerful contributing variable of the posttest practices score. This could be attributed to most of the participants having a master's degree in contrast to participants affiliated with MOHP who had only a bachelor's degree. Also, some of them provide field training for undergraduates in different phases related to child health.

Based on our best knowledge, this is the first trial to evaluate family physicians' KAP toward well-child care for children under five in Egypt. Well-child care issues in the family medicine curriculums for the postgraduate and undergraduate students at the FOM-SCU were both improved based on the results of this study. Only one trained evaluator assessed participants' practices via a valid questionnaire, and this was in order to minimize observer bias. The Head of the Family Medicine Department at the FOM-SCU as well as the academic supervisors who hold a master's degree and are part of the medical doctorate programs there are motivated to participate in this intervention to minimize response bias.

\section{Limitations of the study}

Recruitment of the participated FPs had many difficulties because most of them had multiple official duties. The generalization of the study's result is limited by the lack of randomization. The study also suffered from a limited sample size. 


\section{Conclusions}

The results supported this innovative interventional program was an effective method for enhancing participants' KAP toward well-child care for children under-5 years. Further interventional researches are needed to improve family physicians' practices toward sensory screening, the assessment of $\mathrm{DDH}$, oral health, and anticipatory guidance.

\section{Supplementary Information}

The online version contains supplementary material available at https://doi. org/10.1186/s43054-022-00097-z.

Additional file 1. Outcomes of an intervention program for family physicians on well-child care for children under 5 years in Suez Canal region, Egypt.

\section{Acknowledgements}

Deepest thanks to colleagues who participated in this pre-post intervention.

\section{Authors' contributions}

HA1 designed the study, implemented the study, analyzed the data, and drafted and revised the manuscript. $\mathrm{MA}, \mathrm{HA} 2, \mathrm{BM}$, and $\mathrm{MH}$ contributed to the study design, supervised implementation of the study, contributed to interpretation of study findings, and critically reviewed the manuscript. JS contributed in writing the introduction section and revised the manuscript. All authors read and approved the final manuscript.

\section{Funding}

Suez Canal University financially supported this research. It did not have any role in the design of the study; collection, analysis, and interpretation of data; and in writing the manuscript.

\section{Availability of data and materials}

The datasets used and/or analyzed during the current study are available from the corresponding author on reasonable request.

\section{Declarations}

\section{Ethics approval and consent to participate}

Approval of the research ethics committee affiliated to the Faculty of Medicine, Suez Canal University was obtained before the study commenced and its approval number was 857 . Relevant authorities were contacted for permission to conduct this study in Department of Family Medicine at the Faculty of Medicine, Suez Canal University and its family practice centers. An informed written consent was designed by the researchers and it was taken from all participants prior collecting any data. ClinicalTrials.gov ID: NCT03976778; date of registration: 5.6.2019: retrospectively registered.

\section{Consent for publication}

A written informed consent for publication was obtained from all participants.

\section{Competing interests}

The authors declare that they have no competing interests.

\section{Author details}

1 Department of Family Medicine, Faculty of Medicine, Suez Canal University, 411522 Ismailia, Egypt. ${ }^{2}$ Department of Pediatrics, Faculty of Medicine, Suez Canal University, Ismailia, Egypt. ${ }^{3}$ Faculty of Medicine, Arabian Gulf University, Manama, Bahrain. ${ }^{4}$ Medical Research Center, Kateb University, Kabul, Afghanistan. ${ }^{5}$ New York State Department of Health, Albany, NY, USA.

Received: 16 July 2021 Accepted: 10 January 2022

Published online: 28 February 2022

\section{References}

1. United Nations Children's Fund (2014) The State Of The World's Children 2014 In numbers: every child counts: revealing disparities, advancing children's rights. The SOWC report, UNICEF. http://www.unicef.org/gambia/ SOWC report_2014.pdf. Accessed 13 June 2019.

2. Central Agency for Public Mobilization and Statistic (2018) Section (2): Population. Statistics Yearbook - Population. Giza, CAMPAS. https://www. capmas.gov.eg/Pages/StaticPages.aspx?page_id=5034. Accessed 13 September 2018.

3. Fernald LC, Kariger P, Engle P, (2009) Examining early child development in low-income countries: a toolkit for the assessment of children in the first five years of life. The World Bank Human Development Group. http:// siteresources.worldbank.org/EXTAFRREGTOPEDUCATION/Resources/ 444707-1291071725351/ExaminingECDtoolkitFULL.pdf. Accessed 13 June 2019.

4. Royal Australian College of General Practitioners (2012) Guidelines for preventive activities in general practice, 8th Edition. RACGP, East Melbourne, Australia. http://www.nmml.org.au/content/Document/RACGP\% 20Red\%20Book.pdf. Accessed 13 June 2019.

5. Lin KW (2015) What to do at well-child visits: the AAFP's perspective. Am Fam Physician 91(6):362-364

6. Li P, Rourke L, Leduc D et al (2019) Rourke Baby Record 2017: clinical update for preventive care of children up to 5 years of age. Can Fam Physician 65(3):183-191 PMCID: PMC6515953

7. Smith S, Reji E (2015) Doctors' attitudes to and knowledge and usage of growth charts. S Afr Fam Pract 57(3):219-222. https://doi.org/10.1080/ 20786190.2014.976978

8. Ribeiro AM, Silva RR, Puccini RF (2010) Knowledge and practices regarding child development among primary healthcare professionals. Rev Paul Pediatr 28:208-214. https://doi.org/10.1590/S0103-05822010000200013

9. Figueiras AC, Puccini RF, Silva EM (2014) Continuing education on child development for primary healthcare professionals: a prospective beforeand-after study. Sao Paulo Med J 132(4):211-218. https://doi.org/10.1590/ 1516-3180.2014.1324665

10. Olusanya BO, Roberts AA (2006) Physician education on infant hearing loss in a developing country. Pediatric Rehabil 9(4):373-377. https://doi. org/10.1080/02640410500521615

11. Kemper AR, Clark SJ (2007) Preschool vision screening by family physicians. J Pediatr Ophthalmol Strabismus 44(1):24-44 PMCID: PMC2562224

12. Babli Al, AlDawood KM, Khamis AH (2015) Knowledge, attitude, and practice of general practitioners in Dammam, Saudi Arabia towards vitamin D supplementation to infants. J Fam Community Med 22(3):135-139. https://doi.org/10.4103/2230-8229.163025

13. Douglass AB, Douglass JM, Krol DM (2009) Educating pediatricians and family physicians in children's oral health. Acad Pediatr 9:452-456. https:// doi.org/10.1016/j.acap.2009.09.004

14. Ministry of Health and Population [Egypt], El-Zanaty and Associates [Egypt], and ICF International (2015) Egypt demographic and health survey 2014: key findings. Cairo, Egypt and Rockville, Maryland, USA: Ministry of Health and Population and ICF International. http://dhsprogram.com/ pubs/pdf/fr302/fr302.pdf. Accessed 13 June 2019.

15. Ministry of Health and Population Egypt, Partnership for Maternal, Newborn and Child Health, WHO, World Bank and Alliance for Health Policy and Systems Research (2014) Success factors for women's and children's health. World Health Organization, Egypt. Geneva http://www.who.int/ pmnch/knowledge/publications/egypt_country_report.pdf. Accessed 13 June 2019

16. Ministry of Health and Population [Egypt] (2007) Child health. Pract Guidelines Fam Physicians 1(2007):31-61

17. World Health Organization (2008) Training course on child growth assessment. WHO, Geneva Available from: http://www.who.int/childgrowth/ training/en/. Accessed 13 June 2019

18. Hagan JF, Shaw JS, Duncan P (2008) Bright futures: guidelines for health supervision of infants, children, and adolescents, Third Edition. Pocket Guide. American Academy of Pediatrics, Elk Grove Village, IL https://brigh tfutures.aap.org/bright\%20Futures\%20Documents/BF3\%20pocket\% 20guide_final.pdf. Accessed 2 September 2018

19. Lin KW, Camp M (2010) Universal screening for hearing loss in newborns. Am Fam Physician 81(2):191

20. Mclaughlin MR (2011) Speech and language delay in children. Am Fam Physician 83(10):1183-1188 
21. Mackrides PS, Ryherd SJ (2011) Screening for developmental delay. Am Fam Physician 84(5):544-549

22. Bell AL, Rodes ME, Kellar LC (2013) Childhood eye examination. Am Fam Physician 88(4):241-248

23. Rourke L, Leduc D, Constantin E et al (2013) Getting it right from birth to kindergarten: what's new in the Rourke Baby Record? Can Fam Physician 59(4):355-359 PMCID:PMC3625077

24. Simon GR, Baker C, Barden GA III et al (2014) 2014 recommendations for pediatric preventive health care. Pediatrics 133(3):568-570. https://doi. org/10.1542/peds.2013-4096

25. Rice CE, Braun KV, Kogan MD et al (2014) Screening for developmental delays among young children, National Survey of Children's Health, United States, 2007. MMWR 63(2):27-35 http://www.cdc.gov/mmwr/pdf/ other/su6302.pdf. Accessed 13 June 2019

26. Gürsel Özkurt Z, Balsak S, Çamçi MS et al (2019) Approach of family physicians to pediatric eye screening in Diyarbakır. Turk J Ophthalmol 49(1):25-29. https://doi.org/10.4274/tjo.galenos.2018.10829

27. Barkin SL, Scheindlin B, Brown C et al (2005) Anticipatory guidance topics: are more better? Ambul Pediatr 5:372-376. https://doi.org/10.1367/ A04-2131R1.1

\section{Publisher's Note}

Springer Nature remains neutral with regard to jurisdictional claims in published maps and institutional affiliations.

\section{Submit your manuscript to a SpringerOpen ${ }^{\odot}$ journal and benefit from:}

- Convenient online submission

- Rigorous peer review

- Open access: articles freely available online

- High visibility within the field

- Retaining the copyright to your article

Submit your next manuscript at $\boldsymbol{\nabla}$ springeropen.com 